\title{
Food \& nutrition security versus pollution \& climate change
}

\begin{abstract}
Internationally Food and Nutrition Security [FNS] is linked to climate change, which is used as de-facto global warming. Global warming is not climate change. Climate change is a vast subject that varies with space and time in terms of meteorological parameters. Pollution [air, water, soil \& food] is associated with the population growth, is a major culprit for not achieving nutrition security. Water resources in terms of quantity and quality play the major role but we rarely relate this with climate change \& pollution that play vital role at local and regional level sustainable water resources availability.
\end{abstract}

Understanding all these issues at local and regional levels play an important role in FNS. These issues are discussed in my three recent books published by BSPublications/ Hyderabad, namely

i. climate issues -- Climate Change and its Impacts: Ground Realities,

ii. water resources issues -- Irrigation and Irrigation projects in India: Tribunals, Disputes and Water Wars Perspective, ${ }^{2}$ and

iii. agriculture issues -- 2nd Green Revolution: Agriculture in the perspective of Climate Change.

Climate change issues are used to sharing of green funds and sensationalization of the so-called pseudo impacts of global warming are helping insurance companies to mint money at international level. As a result of these, the science of climate change is corrupted. It is the case with the other two issues, namely water resources and agriculture. All these mutilated the issue of FNS in India.

Under such scenarios, to achieve sustainable FNS in India, governments must put thrust on studies to characterize agro-climate and sustainable water resources availability at local and regional scale. Present day mono-crop system of agriculture will not serve the problem. It must be multi-crop system that includes animal husbandry as a component of farming systems. To achieve food security, food production is not sufficient but governments must see the wastage is minimum. Governments must implement all facets of FNS Act of 2013 by giving priority to locally produced food item. Governments must discourage producing and distributing to needy the food items that are contaminated by pollution and food items adulterated by greedy. Also, in warm tropical country like India, controlling pollution is more important over Paris agreement on controlling $\mathrm{CO}_{2}$ emissions.
Volume 6 Issue 2 - 2017

Jeevananda Reddy S

Formerly Chief Technical Advisor - WMO/UN \& Expert - FAO/ UN, India

Correspondence: Jeevananda Reddy S, Formerly Chief Technical Advisor - WMO/UN \& Expert - FAO/UN, Fellow, Andhra Pradesh Akademi of Sciences, Convenor, Forum for a Sustainable Environment, Email jeevananda_reddy@yahoo.com

Received: October 20, 2016 | Published: January 30, 2017

\section{Introduction}

Providing quality food and poverty eradication are an important issues of concern now a days, is plagued by several compounded factors. International agencies are attributing this scenario to climate change, wherein climate change is used as de-facto global warming. With this the real issues are being sidelined to meet the vested greed. Three important issues that are of primary concern in food and nutrition security, namely climate issues, water resources issues and agriculture issues were discussed by Reddy. ${ }^{1-4}$ These issues in brief as relevant to FNS system are discussed in the present article.

\section{Climate change" is not "global warming}

Reddy $^{1}$ presented detailed scenarios of climate; and a brief is presented below.

\section{Weather \& climate}

Climate is what you expect, weather is what you get. Weather
\& climate respectively refer to short-term \& long-term events in the atmosphere. Averages and extremes in climate in terms of meteorological parameters such as temperature, precipitation, wind, relative humidity, etc for individual stations can be seen in normal books published by meteorological departments using 30 -year period. Thus, temperature is only one parameter of weather and climate. Meteorological parameters do not act independently but they interact with each other in the atmosphere. Change in one parameter has an impact on the other parameters. They vary with climate system. The major components of climate system are the atmosphere, the hydrosphere, the crystosphere, the land surface and the biosphere. General circulation patterns relating to wind systems are superposed on the climate system. These play vital role on local and regional weather and climate. Thus, weather and climate vary with space and time.

\section{Climate change}

Changes in climate are not new. They were there in the past and 
will be there in the future. These are inbuilt variations in nature. However, with the increased interference of humans on nature, the natural variations are being modified at local and regional scales. The combination of these is known as climate change. However, climate change has turned in to political satire of "global warming and carbon credits", which carry billions of dollars to share that is evident even from the 2015 Paris Agreement.

\section{Natural variability consists of}

a. irregular variations that include intra-seasonal \& intra-annual variations and

b. systematic variations expressed by fluctuations or cyclic variations of different durations. These are beyond human control and thus needs to adapt to them. That is exactly what our forefathers did in the case of water resources and agriculture.

II. The man-induced variations have two parts. They are changes through

a. greenhouse effect and

b. non-greenhouse effect. The former has two components, namely

i. global warming since 1951 through anthropogenic greenhouse gases -- Carbon Dioxide from fossil fuel use, and

ii. impact of aerosols from volcanic eruptions. The later is ecological changes associated with the changes in land \& water use and cover, which are defined by

I. "urban-heat-island effect" and

II. "rural-cold-island effect".

\section{Global warming}

The global average annual temperature is derived from the data series over land and ocean but they present non-uniform distribution with both space and time. It is also the case with the Carbon Dioxide. Systematic measurements over oceans started only since 1990 and prior to that the ships used to take observations en-route. Contamination and covering with filth of the ocean waters steadily increasing. From 1973 onwards though satellites started measuring the data but officially the data is available since 1979. For the same period balloon data series are also available. As this data series showed lower annual average temperature over that of ground based measured data, this data was withdrawn from Internet. To show there is significant increase in global temperature due to global warming, some organizations that are maintaining the ground-based data lowered the past data and raised the current data. With all these the past 20years the trend showed a hiatus-pause.

In the global [land \& ocean] temperature anomaly data series of 1880 to 2010 , the trend component presented an increase of $0.6^{\circ} \mathrm{C}$ per Century. Over this trend superposed a 60 -year cycle wherein the sine curve varied between $-0.3^{\circ} \mathrm{C}$ and $+0.3^{\circ} \mathrm{C}$. According to IPCC from 1951 more than half of the global average temperature anomaly is associated with anthropogenic greenhouse gases effect (B/a). Global warming is part of this $(\mathrm{B} / \mathrm{a} / \mathrm{i})$. Even if we assume global warming component as $50 \%$, the trend associated with it is only $0.3^{\circ} \mathrm{C}$ per Century. Even this is basically because of lowering the past data and rising current data. Also, the data is corrupted by having met network concentrated in urban areas and thus overemphasizing urban-heatisland effect and by having sparse met network in rural areas [which is more than twice that of urban areas] and thus underemphasizing rural-cold-island effect. This is not the case with satellite data. Thus, so far the Global warming component is less than $0.15^{\circ} \mathrm{C}$ only. It is insignificant when compared to intra-annual and intra-seasonal changes in temperature and thus has little impact on nature. The global warming component was attributed to cause sea level rise, ice melts, glaciers retreat, impact crop production, cause extreme weather events, rainfall-monsoon changes, etc, etc. There is no way we can expect these with that meager change in temperature.

\section{Destruction of nature}

Nature is being destroyed by both natural disasters such as cyclonic activity, earthquakes, volcanic activity, tsunamis, etc; and activities to meet human greed such as wars, oil-gas-water extraction, physical destruction of ecologically sensitive zones \& destruction of natural water flow systems, etc. Many a time such destruction and their associated changes in nature are attributed to global warming. The reality is quite different. Let me present few cases in this direction.

Flood disasters: Droughts and floods are common to India for that matter world over. Each year one part or the other in India experiences the floods and droughts. The severity of destruction changes with the time of the year, the terrain, with the population growth, and growth in infrastructure. However, with the violation of existing local, state and national laws the destruction is aggravated. This is the case with flood disasters in Uttarkhand in June 2013 and Jammu \& Kashmir in 2014; November-December 2015 floods in Chennai in Tamil Nadu \& Nellore in Andhra Pradesh; and September 2000 floods in Hyderabad in Telangana. All these disasters are associated with the apathy of government agencies as they were unable to control the illegal construction activities along the river beds and converting rainwater channels, rivers, water bodies in to concrete jungle. Now governments are putting the blame on global warming, as it cannot defend against such onslaught by politicians and bureaucrats to protect themselves for wrong doings.

Heat \& cold waves: Heat \& cold waves are also common to certain parts of India in summer \& winter in association with the Western Disturbances, part of General Circulation Pattern. The high-pressure belt over Nagpur region defines the impact zones.

Himalayan glaciers melt: IPCC pronounced in its AR4 Report stating that the Himalayan Glaciers will melt by 2035. Same way Al Gore concluded that Greenland will be ice free in five years. When we questioned UN Secretary General through a letter the veracity on such pronouncements in 2009, these conclusions were withdrawn but only after they received Noble Prize. Government informed to Indian Parliament after Paris meeting in 2015 that $86.6 \%$ of 2181 of Himalayan Glaciers are not receding.

Natural variability: Water is a natural resource, fundamental to life, livelihood, food security and sustainable development; it is also a scarce resource. India has more than $17.11 \%$ of the world's population, but has only $4.6 \%$ of world's water resources with $2.3 \%$ of world's land area. Precipitation and snow melt provide the fresh water; though they are renewable, they are highly variable with space and time; climate change plays vital role in the year to year water availability over different parts of India.

At national level the variability of southwest monsoon precipitation [June to September] appears to be very low - coefficient of variation is $9.9 \%$-- but as we go to smaller areas like state or met sub-division they 
are higher - Coastal Andhra, Rayalaseema \& Telangana sub-divisions, respectively they are $22.2 \%, 28.8 \% \& 23.5 \%$. The rainfall in July, August \& September months over Telangana met sub-division varied highly between $25-50 \mathrm{~mm}$ and more than $400-425 \mathrm{~mm}$ in a month. This is the type of temporal variability we experience. In the case of spatial variation, the drought proneness reaches as high as $60 \%$ of the years in rain shadow zone of Western Ghats like Anantapur-Bellary-Sangly zone to zero percent in good rainfall zones. Without understanding these, people make statements like "unusually extreme".

Destruction of Western Ghats and Himalayas, more particularly foothills, will have disastrous effect on climate, more particularly on precipitation. For example, with the removal of hillock in the Santacruz Airport for the expansion of runways, reduced the rainfall by about $300 \mathrm{~mm}$; but subsequently with densely built tall structures all around brought the rainfall to more or less to the original condition.

Earth's climate is dynamic and always changing through the natural cycle. What we are experiencing now is part of this system. All India Southwest monsoon precipitation, that constitutes $78 \%$ of the annual, since 1871 to date followed a 60 -year cycle. By 1987 , two cycles have been completed. The third cycle started in 1987 and will continue up to around 2046 in which the first 30 years form part of better rainfall period [this will end by 2016] and the next 30years form part of poor rainfall period [starting from 2017]. The frequency of occurrence of floods in the northwestern Indian rivers followed this pattern. Hurricanes and Typhoons also followed this cyclic pattern but hurricanes cycle is in opposite direction to typhoons cycle. It is the case with ocean temperatures in Atlantic and Pacific oceans

However, this is not applicable to individual states or regions For example, Andhra Pradesh a southeastern part of Indian States receives rainfall not only in southwest monsoon season but also in the northeast monsoon season [October to December] and as well as from cyclonic storms in summer [pre-monsoon season, April-May]. Both the monsoons rainfall presented a 56-year cycle but in opposite pattern. The frequency of occurrence of cyclonic activity in Bay of Bengal followed northeast monsoon 56-year cycle pattern. The annual rainfall presented 132year cycle in which in the 66 year below the average cycle part [prior to 1935] presented 12years with excess rainfall $[>110 \%$ of the average] and in 24years with deficit rainfall [ $<90 \%$ of the average]; in the 66-year above the average cycle part [from 1935 to 2000] presented 24 years with excess rainfall and in 12 years with deficit rainfall. The current below the average part of 66 years cycle part will be similar to prior to 1935, started in 2001. Water availability in the Krishna River basin presented similar pattern in terms of surplus \& deficit.

Agro-climate studies: Because of these scenarios, there is a need to carryout detailed agro-climate analysis ${ }^{3}$ at individual station level and region level to develop adaptive measures and as well development of water resources like interlinking of rivers, construction of dams and application of micro-irrigation, etc. In fact such analysis provides basic information such as drought proneness, sustainable growing period and sustainable period for planting.

\section{Sustainable water resources availability}

Water is a God given gift, a renewable source. However, human greed is affecting this life saving source in a variety of ways. Unless we address them, the future will be bleak in getting sustainable water resources availability. Some of these issues are discussed by Reddy [2]. The four pillars of Indian constitution are corrupt to the core. This is the major hurdle in resolving water issues in India. Some of these can be seen from the below discussions.

\section{Tribunals}

To resolve the water resources sharing by riparian states central government appoints the Tribunals headed by retired judges with unfettered powers. This has got both positive and negative repercussions on the riparian states. This is glaringly seen in the case of Krishna River water sharing among the three riparian states. Justice Bachawat headed the first tribunal and Justice Brijesh Kumar headed the second tribunal. The basis for sharing the water is the water availability data series in the catchment area over years. The former followed scientific path but the later followed "technical fraud" path to favour one state over the other. This disrupts the entire irrigation pattern in the affected state. Now, to resolve this issue states are fighting before the Supreme Court of India and before the 2nd tribunal. Everybody forget the fact that this is not a legal issue but it is a technical issue. These are major issues in India. To resolve these issues, the central government must establish a permanent technical body.

\section{Vote bank politics}

Vote Bank politics is the major hurdle in resolving inter-state or intra-state disputes. This has become worse with regional party culture. Let us take the case of two Telugu states. The two Telugu states chief ministers, instead of taking opposition in to confidence, are encouraging defections from opposition parties, so that there will not be any opposition, and thus creating dictatorial rule. "Both of them are intolerant to criticism. The Constitution is blind on this vital corrupt act. For example, Telangana $\mathrm{CM}$ has been planning to spend lakhs of crores on water related projects. The Congress party presented a slide show showing that it is a wasteful expenditure. But $\mathrm{CM}$ warned critics through press, which is most unfortunate. Here the fact is, if the government completes the pending projects, the cost could be brought down to less than $30 \%$ of the 65,000 crores allocated towards Mission Kakatiya and Mission Bhagirtha - though they are ongoing activities and nothing new, they just coined new words. Unfortunately the outsiders do not know the facts on the issues make statements that strengthen the bad policies of ruling parties. Andhra Pradesh CM has initiated temporary capital city building and another lift irrigation project in Pattiseema by wasting public money. Instead of completing the Polavaram Project, which was initiated by the previous government, which has got all statutory clearances for the project and project was allotted to a builder, who is now MP of the ruling party. The amount spent on Godavari \& Krishna Puskaralu and Pattiseema should have helped the building of the main dam and that would have helped the Godavari water reaching Krishna River water through gravity by this time as the right canal was built by the previous government. Instead he initiated a lift to put the water in to right canal - inaugurated three times with three times breeching the canal. This needs Power as it is not gravity system.

\section{Mismanagement of water resources}

The other major issue is the mismanagement of water resources by the government and as well by the people starting from urban water to major dam water irrigation. In modern society people spend lavishly when they get windfall on wealth. It is also seen with water resources. Traditionally the tank water is well managed at village level based on the water availability in the tank. Under vote bank politics this 
disappeared. There is an urgent need to restore such system for efficient utilization of water resources at all levels and at all sectors.

\section{Reduction in water availability due to pollution}

The other major issue in water resources availability, in addition to quantity is quality of water. Chemical input agriculture, industry, urban culture, etc are contributing to reduction in quality water availability. In and around urban areas using such water crops are produced and supplied to urban areas for consumption and thus causing severe health hazards.

\section{2nd green revolution must be a sustainable system}

Reddy ${ }^{4}$ presented details on the $2^{\text {nd }}$ green revolution issues.

\section{Sustainable FNS system}

The traditional agriculture was soil and climate driven farming systems that encompasses the animal husbandry. It provided socio-economic, food and nutrient security with the healthy food. Those were the "Golden Days" in the history of farming. It was an environment-friendly system and was highly successful \& sustainable. No pollution, no worry about seeds and fertilizer adulteration as they used good grain as seed and compost of farmyard manure and green manure as fertilizer. This system of agriculture was clouded by the chemical inputs agricultural technology in 1960s.

\section{Unsustainable FNS system}

Following growth in population the food production balance got disrupted and in order to find a solution to ever growing problem, 60 s saw the chemical inputs technology and later genetically modified seed technology entering India in the form of much eulogized Green Revolution Technology. With the help of those technologies, food security was achieved up to an extent. But, it came at huge costs with disastrous impact on environment. The Green Revolution increased the production substantially in terms of quantity but failed to achieve the quality of traditional agriculture in terms of food and fodder. The technology includes high yielding seeds, chemical inputs (fertilizers \& pesticides, insecticides, herbicides, etc.) and irrigation. However, newly developed high yielding seeds used in 'Green Revolution Technology' created new problems hitherto unknown to farmers. Use of chemicals in the crop management caused the cost of production jump several folds. Here entered government's input subsidy, a huge component.

\section{Productivity}

Studies on paddy/rice production figure of 70 s \& 80s in Andhra Pradesh [undivided] revealed that the traditional paddy under irrigation yielded $1300 \mathrm{~kg} / \mathrm{ha}$; by adding high yielding seed this increased by $500 \mathrm{~kg} / \mathrm{ha}$; and by adding chemical fertilizers the yield level rose further by $2000 \mathrm{~kg} / \mathrm{ha}$. That means total yield achieved was $3800 \mathrm{~kg} /$ ha under farmers' fields. This was far less than research station yields of 5000 to $6000 \mathrm{~kg} / \mathrm{ha}$. The present average yields of farmers' field are $2600-2800 \mathrm{~kg} / \mathrm{ha}$ as the yield curve flattened since $1984-85$. Only increase in area under irrigation contributed to additional increase in production after 1984-85.

Studies clearly reflect that high yielding seeds introduced during and after the Green Revolution were tailored to chemical fertilizers under irrigation. This severely affected dry-land agriculture that constituted around $60 \%$ of the cultivated land. This lead dry-land farmers migrating to urban areas as the dry-land agriculture with high input costs became unsustainable and non-remunerative.

\section{GMOs role in productivity}

Forty years later, genetically modified (GM) seed entered into Indian agriculture system. Most innovations in this have been profitdriven rather than need-driven. Global seed industry is controlled by four western MNCs and at the same time GM seed industry is in one MNC's hands. The GM technology responds to the need of GM companies to intensify farmers' dependence upon seeds protected by the so-called intellectual property rights, which conflicts directly with the age-old rights of farmers to reproduce, share or store seeds. In fact, to get overnight profits, the Indian seed companies changed their high yielding seed into GM seed and ensured that non-GM seed is "not sold in the market". This has resulted markets flooding with spurious/ adulterated GM seed varieties under different names.

One such GM Seed, Bt-cotton, is in use since 2002-03 in India. Use of chemical fertilizers and irrigation increased the area under cotton under GM seed and reduced the area under non-GM seed without much yield advantage. The Bt-cotton area during 2002-03 to 2010-11 increased from 0.04Lha to 17.95Lha in Andhra Pradesh and at the same time area under non-Bt-cotton reduced from 8.03Lha to 0.22Lha. At all India level area under cotton increased from 7.667Mha to 11.161Mha. During the same period the yields increased from 212.5 to $545.7 \mathrm{~kg} / \mathrm{ha}$ in Bt- and 229.1 to $919.5 \mathrm{~kg} / \mathrm{ha}$ in non-Bt at Andhra Pradesh level. At all India level cotton yields increased from 302 in 2002-03 to 554 in 2007-08 and there onwards declined to $475 \mathrm{~kg} / \mathrm{ha}$ in 2010-11. That is, the productivity has been stagnant for the past five years. The yield increase is associated with the high yielding cotton seeds of both GM \& non-GM to chemical inputs and irrigation.

\section{Newer agriculture technologies impact on environment}

Newer technologies were portrayed as a solution to all human problems, especially the problem of hunger and poverty forgetting their impact on the environment. However, the use of chemical inputs reduced the quality of food and created bad impact on environment. This "western profit driven" chemical input technology was found to be more dangerous on long-term, over the short-term gains. It has destroyed the environment drastically- soil degradation \& salinization, health hazards to human, animal \& plant life with air, water, soil \& food pollution. The pollution related health hazards necessitated the introduction of drug manufacturing industry and establishment of hospitals who in turn cause air and water pollution, turning this into a vicious circle. Even with all these ill effects, the yield growth curve has flattened after 1984-85.

In fact, the chemical input technology is like "scratching the head with fire". When this technology was introduced nobody knew that this technology is going to create such environmental catastrophe. Even the Nobel Prize awarding organization was not aware of this while awarding Nobel Prize to Norman Borlaug. We must not forget the fact that GM technologies also work under chemical inputs - irrigation only; and thus those impacts also apply to GM seed technology. In addition, GM seed technology presents several other impacts on biodiversity, contamination, re-generation, herbicide-tolerant weeds, new pests-diseases etc. Because of some 
of these, in USA \& China GM crops were not permitted to grow in some zones. In India GM crops are grown everywhere including prohibited zones. There are several other aspects like food safety and ethics. India has no mechanism to study such aspects. Thus, with the GM seed technology, the cure has become more dangerous than the disease.

\section{What is to be done}

To achieve sustainable agriculture, therefore, the governments must change the policy on agriculture. The policy must include low input costs, pollution free quality food technology such as organic inputs under cooperative farming setup. This not only brings down the cost of production but also reduces drastically man hours spent on procuring basic inputs by individual farmers, improves the utilization of natural resources and thus helps to reach sustainable agriculture.

In fact progressive farmers with traditional wisdom have developed technologies and achieved far higher yields than the research station yields and received national and international awards/rewards and recognition but neither the government nor the scientists showed any interest, though there is a mechanism in government departments, to stabilize that technology and provide packages to farmers to achieve environmental friendly progress in agriculture. The states and central governments must allocate sufficient funds to collect traditional inventions of progressive farmers and integrate these in traditional technology to achieve the 2nd Green Revolution that safeguards the environment and provide food safety, biosafety, food \& nutrient security; and protect the farmers from committing suicides and provide socio-economic security.

Also, as proposed in new Food Security Bill, distribution of locally produced foods can be given under PDS by which the food subsidy component will come down substantially. This shall also reduce wastage and loss in FCI storage facilities and transportation.

\section{Few suggestions to achieve sustainable FNS}

In addition to the three broader issues discussed above, the following are the few other points that help to build sustainable FNS system in Indian context.

Food and Nutrient security Bill was passed in 2013 by the Indian Government. This Act integrated all activities that come under food and nutrition security. This bill caries several components of food and nutrient supplements to needy. However, with the change of governance at center and state levels, these are not moving as speculated in the bill. This needs implementation in true spirit. Under PDS [public distribution] system the government though introduced minor millets, the state governments are not coming forward to implement this in terms of production, procurement and supply under PDS. This must be implemented. The minor millets are considered as pollution free foods.

UN agencies must put pressure on Indian Government to discourage in supplying polluted food such as wheat and rice under PDS system. Also, put pressure on controlling adulterated food supplies, which are common all over India.

Food production in quantity alone is not the parameter to achieve food security but there are several other factors involved, namely food wastage - FAO reported it is around $30 \%$ but from my calculation it is around 40 to $50 \%$ in India --, needs better storage facilities, minimum transport losses. To achieve this governments must encourage locally produced foods under food and nutrient security schemes.

Environmental groups must play a role in eradicating polluted food production and consumption as well adulterated food production and distribution in which they create awareness among people. Government must discourage mono-crop system of agriculture under high chemical inputs and under intensive irrigation system, as this will hamper linking of animal husbandry under farming systems that will be a major input to nutrient security aspect.

\section{Acknowledgements}

None.

\section{Conflict of interest}

The author declares no conflict of interest.

\section{References}

1. Reddy SJ. Climate Change and its impacts: Ground Realities. Hyderabad, India: BS Publications; 2016. 292 p.

2. Reddy SJ. Irrigation and irrigation projects in India: Tribunals, disputes and water wars perspective. Hyderabad, India: BS Publications; 2016. $154 \mathrm{p}$.

3. Reddy SJ. Agroclimatic/Agrometeorological Techniques as applicable to dry-land agriculture in developing countries; 1993. $205 \mathrm{p}$.

4. Reddy SJ. $2^{\text {nd }}$ Green Revolution: Agriculture in the perspective of climate change. Hyderabad, India: BS Publications; 2016. 220 p. 